University of Montana

ScholarWorks at University of Montana

Public and Community Health Sciences Faculty

Publications

Public and Community Health Sciences

$2-2008$

\title{
Air Toxics under the Big Sky: A Real-World Investigation To Engage High School Science Students
}

\author{
Earle Adams \\ University of Montana - Missoula \\ Garon C. Smith \\ University of Montana - Missoula, garon.smith@umontana.edu \\ Tony Ward \\ University of Montana - Missoula, tony.ward@mso.umt.edu \\ Diana Vanek \\ University of Montana - Missoula \\ Nancy Marra \\ University of Montana - Missoula \\ See next page for additional authors \\ Follow this and additional works at: https://scholarworks.umt.edu/pchs_pubs \\ Part of the Public Health Commons \\ Let us know how access to this document benefits you.
}

\section{Recommended Citation}

Adams, Earle; Smith, Garon C.; Ward, Tony; Vanek, Diana; Marra, Nancy; Jones, David; Henthorn, Melissa; and Striebel, Jim, "Air Toxics under the Big Sky: A Real-World Investigation To Engage High School Science Students" (2008). Public and Community Health Sciences Faculty Publications. 1.

https://scholarworks.umt.edu/pchs_pubs/1

This Article is brought to you for free and open access by the Public and Community Health Sciences at ScholarWorks at University of Montana. It has been accepted for inclusion in Public and Community Health Sciences Faculty Publications by an authorized administrator of ScholarWorks at University of Montana. For more information, please contact scholarworks@mso.umt.edu. 


\section{Authors}

Earle Adams, Garon C. Smith, Tony Ward, Diana Vanek, Nancy Marra, David Jones, Melissa Henthorn, and Jim Striebel 


\title{
To Engage High School Science Students
}

\author{
Earle Adams* and Garon Smith \\ Department of Chemistry, The University of Montana, Missoula, MT 59812; *earle.adams@umontana.edu
}

\author{
Tony J. Ward, Diana Vanek, and Nancy Marra
}

Center for Environmental Health Sciences, The University of Montana, Missoula, MT 59812

\section{David Jones}

Big Sky High School, Missoula, MT 59804

\section{Melissa Henthorn}

Hellgate High School, Missoula, MT 59801

\section{Jim Striebel}

Corvallis High School, Corvallis, MT 59828

In order to widen the scope of science education to a broader student base, some educators have ventured away from lecture-based teaching models to one that is more "participatory" in nature. This allows the inquisitive nature of the students to play a larger role in the learning process $(1-5)$. More and more, educators employ project-based learning (PBL) as a mechanism to engage students $(6-9)$. Although educators unilaterally recognize the positive outcomes from PBL curricular components, the practical question always arises: "How do you introduce this approach in the time-rigid and resource-poor environments of most K-12 schools?" This paper summarizes our solution to PBL's time and resource challenge issues. It describes a collaborative, real-world research project involving researchers from The University of Montana (UM) and teachers and students from three regional high schools.

\section{PBL Approaches for Teaching and Learning Science}

Known as "Air Toxics under the Big Sky", a research consortium has been established among scientists and faculty from UM's Center for Environmental Health Sciences (CEHS) and the Department of Chemistry, in collaboration with three local high schools (Big Sky High School, Hellgate High School, and Corvallis High School) and a tribal college (Northwest

List 1. Four Main Components of PBL Models

1. A question that identifies a real problem to explore

2. Real products or data that emerge from the investigation

3. Collaboration with a team of members, peers, or mentors in a community

4. Cognitive tools students can use to support the investigative process
Indian College, Lapwai and Kamiah, ID campuses). The project incorporates community-based participatory research into each school's curriculum, while also striving to increase diversity in science (10-11). The Air Toxics under the Big Sky project incorporates all the components of a problem-based learning model (see List 1) and deals with an environmentally and geographically relevant issue.

\section{Examples of PBL Science Collaborations}

Research models involving university scientists, high school teachers, and students are becoming more common. A wetlands project involving University of Maine researchers, high school teachers, and students established a long-term wetlands monitoring program that collects and distributes data on interactive Web sites (12). This project addresses educational standards and inspires students to pursue science, while also producing relevant data on wetland systems that have not been previously studied. An outreach project in France between a research institute and a lycée (high school) introduced polymer chemistry through a series of lectures to show the historical and present relevance of science (13). The project then progressed to students working with polymer researchers while their teacher taught chemical reactions in class to connect lecture principles to the experiments.

In Israel a PBL life science project between a high school student group and researchers at a science institute produced student reports that resembled Master's level research as well as publications in the scientific literature (14). A program at Duke linked a whole science department with high school teachers in implementing pharmacology modules in their biology and chemistry classes. Topics included drug development research, acids-bases with respect to cocaine addicts, drug testing, and military pharmacology. The study showed an increase in student performance on biology and chemistry exam questions (15). A common factor in all these studies is that the interest of the student increased significantly with direct experience doing scientific research. 
Texas high school students in a pilot program used the U.S. Environmental Protection Agency (EPA)'s air quality tool, "Tools for Schools", with an air quality method developed for California schools (16-17) to monitor the school's indoor air quality relative to volatile organic compounds (VOCs), mold, and formaldehyde. The Texas study showed that the EPA's Tools for Schools can successfully be implemented within a school's curriculum because of its community-based participation by students and teachers (16). The Air Toxics under the Big Sky project has some similar qualities and goals as the Texas high school study, although with more interaction between students and researchers. It focuses on air quality within and directly outside students' homes, as well as some sampling conducted within their school. The Air Toxics under the Big Sky project allows students to benefit from an independent research experience linking science, research, and local environmental issues.

We have completed our fourth year of the project. Initially, a high school junior designed a study to sample VOCs at the homes of 14 classmates during the 2003-2004 academic year. The investigation constituted the student's topic for his Applied Problems in Science (independent research) course at Big Sky High School. Given the success and feasibility of the pilot study, the project expanded to two additional area high schools and a tribal college during 2004-2005. This involved a total of 69 high school and tribal college student research partners. Student participation rose to nearly 100 students in the 2005-2006 academic year. We see this as a long-term project that will be built upon and expanded by future students during each new school year, and as new schools are added. This model will foster a long-term scientific collaboration between UM, Montana high schools and area tribal colleges, and establish students as regular and valuable contributors to the scientific community while exposing them to environmental issues involving chemistry, science, and health.

\section{Experimental Methods}

\section{Phase 1: Orientation and Background}

The Air Toxics under the Big Sky project begins early in the school year when a UM researcher goes to each of the participating schools and makes a presentation to the students on air pollution, and why it is important to them as inhabitants of western Montana. We describe sources of air pollutants, what EPA is doing to reduce air pollutants from industry and area sources (cars and trucks), and discuss air pollutants in the indoor environment. The presentation then focuses on training teachers and students on air sample collection procedures for both indoor and outdoor environments, covering the logistics and protocols that are necessary for quality assurance-quality control concerns. Additionally, a questionnaire is used to elicit information on potential sources of air toxics inside each household. It contains an optional section that seeks to identify the incidence of asthma and other respiratory diseases among the home's residents.

\section{Phase 2: Air Sampling and Analyses}

During the data-gathering phase, students simultaneously collect both indoor and outdoor air samples at their residences following the modified air sampling procedures in EPA Compendium Method TO-2 (18), and protocols found in the online supplement. For the first two years, the air-sampling program focused on quantifying the concentrations of 53 different VOCs inside and outside of students' homes. Several of the VOCs measured are components of gasoline and are found on EPA's list of 188 Hazardous Air Pollutants (19). Many of these VOCs are released into the environment during fuel transfers as well as from automobile tailpipe emissions. The sampling equipment utilized in this portion of the program consists of constant flow personal pumps (SKC Model 222-3) with reusable Supelco Carbotrap 300 sorbent tubes. Sorbent tubes are initially cleaned and prepared at UM, and then delivered to the schools prior to sampling. Pumps are then calibrated before being assigned to students for resident sampling. Each home is sampled for 12hour periods, with the goal of at least three times throughout the school year (fall, winter, and spring for a seasonal comparison). During sampling, the students turn on the pumps at 7 am and discontinue sampling at $7 \mathrm{pm}$, thus capturing the morning and evening rush hours. Global positioning system (GPS) coordinate points are also collected at each sample location.

The exposed sample tubes are returned to UM where they are analyzed by thermal desorption-gas chromatography-mass spectrometry (TD-GC-MS). Following analysis of the samples at $U M$, final results of the raw air pollutants data $\left(\mathrm{ng} / \mathrm{m}^{3}\right)$ are reported back to the high school students so that they can synthesize chemical stories for their own communities.

\section{Phase 3: Data Analysis and Synthesis}

The third phase occurs during the spring semester after students have had the opportunity to review their data. Each participating class breaks into three or four groups. Students generate research questions and hypotheses and subsequently use their VOC, GPS, and questionnaire data to test them. Examples of actual student research questions include:

1. Is there a relationship between indoor air concentrations and the incidence of asthma in each residence?

2. Is there an indoor-outdoor concentration relationship?

3. What seasonal variations are there with respect to the indoor and outdoor concentrations?

4. What geographic variations are suggested by the combination of air toxic concentrations and GPS data?

5. Is there a correlation between the air toxic concentrations and the local meteorological data?

6. Is there a relationship between what sorts of chemicals and equipment are stored in or adjacent to the individual residences (i.e., paints, solvents, etc.)?

\section{Phase 4: Presenting the Results}

Ultimately, all results and conclusions are shared among the entire research consortium at a UM-hosted symposium. The symposium audience includes the student participants and their teachers, as well as UM faculty, researchers, and public officials from county, state, and federal agencies. A panel of celebrity judges award gift certificates after hearing and rating the group presentations. Following the individual presentations, air quality professionals suggest ways to mitigate common sources of indoor air pollutants. All of the students' electronic presentations and pictures from the event are then posted on the Air Toxics under the Big Sky Web site (20).

Field trips and guest lectures enhance the overall effect of the project. At least once during the school year, the classes 
from the various high schools are brought to UM to see the technologies, instrumentation and laboratories available on campus. Throughout the year, UM researchers from ancillary disciplines conduct seminars for the partner schools to introduce related areas of research being conducted at UM. For example, an epidemiologist went to Big Sky High School in 2007 to talk about the health effects of exposure to air toxics, while an immunologist went to Corvallis High School to talk about how pollutants effect the body at the cellular level.

\section{Results}

Air quality and its link to asthma and respiratory disease is a ready-made case scenario for a student-based PBL problem. The overall research objective for the Air Toxics program is to gather data from which we can assess the impacts of air quality on asthma and other respiratory diseases in Montana residents. VOCs are among the key air toxics listed in the 1990 amendment to the Clean Air Act that pose a significant threat to public health, yet have unknown roles in the development or worsening of asthma (21). According to the EPA's 2002 Asthma Research Strategy, studies are needed to more accurately assess exposures and biological effects, and to manage the risks associated with individual air toxics or combinations of compounds. Asthma is now one of the leading reasons for hospital visits in poor, urban areas (22). The link between air quality and asthma is a significant environmental health concern in western Montana where severe temperature inversions occur frequently in winter. During such inversions, cold air sinks into mountain valley bottoms overnight and traps wood-burning stove smoke and motor vehicle exhausts in the ground-level layer of air.

In this study students found that toluene is the most abundant compound identified in both the indoor and ambient environments (out of the compounds measured in this study). Students have also consistently measured higher concentrations indoors compared to those levels found outdoors, with VOC concentrations about six times higher indoors compared to those simultaneously measured directly outside their homes.

As outlined in List 1, PBL model components include collaboration between students and faculty or researchers at a number of higher levels. In our Air Toxics project, students have contact with active professional researchers, public health officials, policy makers, graduate students, undergraduate students, and out-of-school student peers while studying a "real-world" local environmental problem. Students typically work in groups of four with their teacher's guidance in developing a hypothesis and appropriate experimental methods. These mentoring interactions have stimulated a number of students to choose a science-oriented career path. To date, four students from our collaborative high schools attend UM and have elected to continue their air toxics research at the university level. Thus, in a very short span, we have already established "a western Montana pipeline" representing the transition of our high school student partners into undergraduate research partners at the university. The Air Toxics under the Big Sky project has proven to be a successful recruiting tool for UM in bringing in talented science students for continuing education.

Another component of a PBL model is generation of a product. The data produced by high school students have been added to an asthma registry database created and maintained by UM's CEHS. This registry aggregates data from across western
Montana and interfaces with information on the incidence of asthma and respiratory diseases. Through these combined records, we seek a better understanding of risks posed by air toxics in western Montana. Student efforts and the data generated from this program have been shared with Montana's Department of Environmental Quality, the Missoula City-County Health Department, and the Montana Department of Health and Human Services. Collectively, it can guide communities and policy makers with the essential data needed to prioritize effective action in reducing exposures to air toxics in their specific locales.

Finally, the last component of a PBL model is the use of cognitive tools to support the process of research and inquiry. Students must interpret their data and find ways to link the data to variables that may factor in to their hypotheses.

\section{Program Successes}

The success of this outreach project relies critically on the work and volunteer effort of our high school teacher partners. In return for their efforts, we have endeavored to help them develop professionally. Since the inception of this project in 2003, two of our three teachers have received Toyota Tapestry grant awards, a Toshiba America Foundation award, and a Vernier award. One of the teachers was awarded the American Chemical Society (ACS) Northwest Regional Teacher of the year award. In 2005, a group of eight UM researchers, administrators, and a high school teacher took part in an NSF summer institute on science and civic engagement-SENCER (Science Education for New Civic Engagements and Responsibilities) (23). UM was one of only three groups with high school partners in attendance. This diverse group has begun a systematic design of high school curricular materials to streamline bringing new schools into the consortium.

The Air Toxics under the Big Sky project allows students to benefit from an independent research experience linking science, research, and local environmental issues. The mentors in this project have found it rewarding to see young students excited about scientific research and engaging in a real environmental problem in their community. Our third annual symposium featured over 100 students who presented their data in front of their peers, university members, and public officials. Throughout the symposium, students were treated to a half-day of talks, poster presentations, discussion-answer periods, lunch, and awards for best presentations. Response from students was very enthusiastic on the scientific venue and experience.

\section{Conclusion}

The Air Toxics under the Big Sky project allows student participants to learn how air pollution episodes are measured, and educates students on the human health dimensions that accompany acute and chronic exposures to air toxics. Students are exposed to modern instrumentation and sampling equipment. Having learned basic GC-MS theory in their chemistry classes, students apply the instrument theory to solving a relevant problem, thus alleviating the disconnect that students so often experience between classroom activities and their everyday activities. Finally, students have protracted contact with active professional researchers while studying a "real-world" environmental problem. These mentoring interactions can stimulate students to choose a science-oriented career path. 
From the perspective of an institution of higher learning, $\mathrm{UM}$ is promoting the engagement of young students in research conducted in an area not previously studied in Montana, namely, measuring the levels of air toxics inside residential homes. This project is nicely embedded within the university's larger goal of correlating ambient and indoor air pollution with respiratory disease. This project contributes a significant amount of data to the UM CEHS environmental public health tracking database. Ultimately, this database can be used both by UM's environmental chemists and health professionals, and as a learning tool in the science classroom.

\section{Future Directions}

What is in the future of this project and its chances for sustainability? Here are two new directions for the Air Toxics under the Big Sky project.

\section{Studying Fine Airborne Particulate Matter}

First, it should be noted that sampling for VOCs is just one possibility for sampling as part of this project. The Air Toxics under the Big Sky project has recently incorporated air sampling for fine particulate matter $\left(\mathrm{PM}_{2.5}\right.$, airborne particulate matter $\leq 2.5 \mu \mathrm{m}$ in diameter) into the program at Big Sky High School during the 2005-2006 school year ( 15 homes sampled indoors), with expansion of $\mathrm{PM}_{2.5}$ sampling (coupled with the already existing air toxics sampling) into an additional participating high school during the 2006-2007 academic year. Exposure to fine particulate matter $\left(\mathrm{PM}_{2.5}\right)$ is a national health issue because of the role it plays in exacerbating respiratory diseases. They are a special concern in western Montana because so many rural communities use wood stoves for heating throughout the winter. Then, too, large forest fires during the summer months release large $\mathrm{PM}_{2.5}$ plumes into the regional airshed. Recruiting more rural schools and students to participate in the $\mathrm{PM}_{2.5}$ studies will provide a broader statistical background on particulate matter effects in western Montana.

\section{Expanding Student Participation}

Second, we now envision expanding student participation into elementary and middle school grades. In 2006, a group of high school students participating in the Air Toxics under the Big Sky project collected air samples at an elementary $(\mathrm{K}-5)$ school in Missoula, and thus became mentors to elementaryage children. A study in Brazil showed that high-school-aged students worked remarkably well as mentors to younger children on developing environmental awareness (24). Using young peer mentors deepens the mentors' learning as well as providing an avenue for increasing students' awareness and initiating behavioral changes to protect the environment.

With the incorporation of $\mathrm{PM}_{2.5}$ sampling into schools in 2006, the Air Toxics under the Big Sky program has evolved into the "Big Sky Model". In the future we will incorporate other pollutants to be sampled within the homes of students (carbon monoxide, radon, pollen, and mold), and revise the questionnaire to elicit information on health effects related to these environmental hazards. The goal of implementing and refining the "Big Sky Model" over the next five years into a more broadly adopted science curriculum will be as challenging as it has been rewarding.

\section{Literature Cited}

1. Barab, S. A.; Hay, K. J. Res. Sci. Teach. 2001, 38 (1), 70-102.

2. Barab, S. A.; Hay, K. E.; Barnett, M. G.; Keating, T. J. Res. Sci. Teach. 2000, 37 (7), 719-756.

3. Blumenfeld, P. C.; Marx, R. W.; Soloway, E.; Krajcik, J. Educ. Researcher 1996, 25 (8), 37-40.

4. Lehrer, R.; Horvath, J.; Schauble, L. Interact. Learn. Environ. 1994, 4 (3), 219-231.

5. Roth, W. M.; McGinn, M. K. J. Res. Sci. Teach. 1998, 35 (2), 213-235.

6. Heppert, J.; Ellis, J.; Robinson, J.; Wolfer, A.; Mason, S. J. Coll. Sci. Teach. 2002, 31(5), 322-326.

7. Shelton, J. B.; Smith, R. F. Res. Sci. Technol. Educ. 1998, 16 (1), 19-30.

8. Cruickshank, B. J.; Olander, J. J. Coll. Sci. Teach. 2002, 31 (6), 374-377.

9. Ram, P. J. Chem. Educ. 1999, 76, 1122-1126.

10. Moore, J. W.J. Chem. Educ. 2006, 83, 823.

11. Middlecamp, C. H.; Jordan, T.; Shachter, A. M.; Lottridge, S.; Oates, K. K. J. Chem. Educ. 2006, 83, 1301-1307.

12. Calhoun, A. J. K.; McGarry, M. A.; Reeve, A. J. Geosci. Educ. 2003, 51 (4), 387-397.

13. Carriere, F. J.; Abouaf, M. J. Chem. Educ. 1997, 74, 61-63.

14. Marchaim, U.J. Biol. Educ. 2001, 35 (4), 178-182.

15. Schwartz-Bloom, R. D.; Halpin, M. J.J. Res. Sci. Teach. 2003, 40 (9), 922-938.

16. Petronella, S. A.; Thomas, R.; Stone, J. A.; Goldblum, R. M.; Brooks, E. G. J. Environ. Health 2005, 67 (10), 35-42.

17. Spielman, H.B. Follow-up Industrial Hygiene Survey: Indoor Air Quality (HAS Project No. O0LA331)[unpublished report]; Saugus Union School District: Santa Clarita, CA, 2000.

18. U.S. EPA. Compendium Method TO-2. Method for the Determination of Volatile Organic Compounds in Ambient Air by Carbon Molecular Sieve Adsorption and Gas Chromatography/Mass Spectrometry $(G C / M S)$, revision 1.0; Office of Research and Development: Washington, DC, 1984.

19. U.S. EPA's List of 188 Hazardous Air Pollutants. http://www.epa. gov/ttn/atw/188polls.html (accessed Nov 2007).

20. Air Toxics under the Big Sky. http://www.umt.edu/cehs/k12_outreach.html (accessed Nov 2007).

21. U.S. EPA. Asthma Research Strategy. Office of Research and Development: Washington, DC, 2002; EPA 600/R-01/061. http:// cfpub2.epa.gov/ncea/cfm/recordisplay.cfm?deid=54825 (accessed Nov 2007).

22. Corburn, J.; Osleeb, J.; Porter, M. Health and Place 2006, 12, 167-179.

23. Science Education for New Civic Engagements and Responsibilities (SENCER). http://www.sencer.net/(accessed Nov 2007).

24. Madruga, K.; da Silveira, C. F. B. J. Clean. Prod. 2003, 11, 519-525.

\section{Supporting JCE Online Material}

http://www.jce.divched.org/Journal/Issues/2008/Feb/abs221.html

Abstract and keywords

Full text (PDF) with links to cited URLs and JCE articles

Supplement

Instructions for students

A student worksheet 